\title{
Antitumor and anti-angiogenic potentials of isolated crude saponins and various fractions of Rumex hastatus D. Don.
}

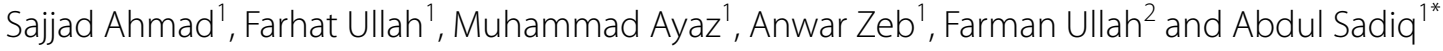

\begin{abstract}
Background: Cancer, being the foremost challenge of the modern era and the focus of world-class investigators, gargantuan research is in progress worldwide to explore novel therapeutic for its management. The exploitation of natural sources has been proven to be an excellent approach to treat or minify the excessive angiogenesis and proliferation of cells. Similarly, based the ethnomedicinal uses and literature survey, the current study is designed to explore the anti-tumor and anti-angiogenic potentials of Rumex hastatus. Anti-tumor and anti-angiogenic activities were carried out using potato-disc model and chorioallantoic membrane (CAM) assay respectively. Moreover, $R$. hastatus was also assessed for antibacterial activity against Agrobacterium tumefaciens (tumor causing bacterial strain). The positive controls used in anti-tumor, anti-angiogenic and antibacterial activities were vincristine sulphate, dexamethasone and cefotaxime respectively.

Results: The crude saponins (Rh.Sp), methanolic extract (Rh.Cr) and other solvent extracts like $n$-hexane (Rh.Hex), chloroform (Rh.Chf), ethylacetate (Rh.EtAc) and aqueous fraction (Rh.Aq) exhibited notable anti-tumor and anti-angiogenic activities. In potato tumor assay, the chloroform and saponin fractions were observed to be the most effective showing 86.7 and $93.3 \%$ tumor inhibition at $1000 \mu \mathrm{g} / \mathrm{ml}$ with $\mathrm{IC}_{50}$ values 31.6 and $18.1 \mu \mathrm{g} / \mathrm{ml}$ respectively. Similarly, these two samples i.e., chloroform and saponins also excelled among the entire test samples in anti-angiogenic evaluation exhibiting $81.6 \%\left(I C_{50}=17.9 \mu \mathrm{g} / \mathrm{ml}\right)$ and $78.9 \%\left(I C_{50}=64.9 \mu \mathrm{g} / \mathrm{ml}\right)$ at $1000 \mu \mathrm{g} / \mathrm{ml}$ respectively. In contrast, the antibacterial investigations revealed a negligible potential against $A$. tumefaciens.

Conclusion: Based on our results we can claim that $R$. hastatus possesses both anti-tumor and anti-angiogenic potentials. In all of the solvent fractions, Rh.Chf and Rh.Sp were most effective against tumor and angiogenesis while having negligible activity against A. tumefaciens. It can be concluded that Rh.Chf and Rh.Sp might be potential targets in the isolation of natural product having anti-neoplastic action.
\end{abstract}

Keywords: Rumex hastatus, Agrobacterium tumefaciens, Saponins, Angiogenesis, Tumor

\section{Background}

In each and every era, the world has to face various challenges. The challenge to survive and to combat various health anomalies is the foremost challenge of each era. Similarly, in the context of health anomalies, tumor is the most challenging threat to the current era [1]. Tumor is mainly characterized by abnormal and excessive

\footnotetext{
*Correspondence: sadiquom@yahoo.com

${ }^{1}$ Department of Pharmacy, University of Malakand, Chakdara, Dir (L),

Khyber-Pakhtunkhwa (KPK) 18000, Pakistan

Full list of author information is available at the end of the article
}

proliferation of cells, which progressively overrun and disrupt the neighboring cells. The angiogenesis i.e., formation of new blood vessels also occurs along with the proliferation of cells which rarely occurs in normal tissues except in the wound healing and embryogenesis [2]. It has been obviously manifested that excessive angiogenesis leads to several pathological conditions including cancer, atherosclerosis, arthritis, ovarian cyst and osteomyelitis [3]. Tumor progressions always require increase in number of blood vessels and similarly decrease in number of blood vessels in milieu leads to dormancy of 
tumor. Angiogenic pathway is a sound target to obstruct the excessive proliferation of cells because the nutrients and growth factors are supplied through blood vessels to the tumor cells. Anti-angiogenesis is probably one of the leading strategies of the emerging oncologists to combat cancer [4]. Several chemotherapeutic agents are used against the angiogenesis-dependent pathophysiological conditions especially against tumor. The synthetic chemotherapeutic agents being associated with plethora of hazardous effects are discouraged and the investigators are trying to explore bioactive agents derived from natural sources to cure tumor and other lethal diseases [5-7]. A leading source of natural bioactive compounds i.e., plants have been gaining much more attention of the researchers for their good efficacy and low toxicity $[8,9]$.

Potato tumor assay has been conducted on several plants of various families with prominent results $[10,11]$. Similarly, strong anti-angiogenic activity has also been demonstrated by several plant species following chorioallantoic membrane (CAM) assay [12, 13]. Numerous bioactive compounds have been isolated from various plants and have been evaluated against tumor with good results [14].

In the plants kingdom several families and genera have been evaluated against tumor and one of the genera i.e., Rumex has been proven to be a good source of antitumor compounds [15-17]. Several compounds have been isolated from Rumex hymenosepalus having antitumor potential [18]. Moreover, the Rumex species are being used in wound healing, astringent $[19,20]$, antiasthmatic, antitussive, anti-tumor and antioxidant [1]. It is evident that almost all the species of a specific genus resembles considerably due to genome similarity among the species of the same genus [21]. Similarly, $R$. hastatus has been traditionally used against pimples, wounds, scorpion stings, foot and mouth diseases, eye diseases, giddiness and insanity [22]. It has also been reported to be used traditionally as laxative, alterative, tonic, in rheumatism [23], in skin diseases, piles, bilious complaints and lungs bleeding [24]. The juice of $R$. hastatus is used to treat blood pressure [25], in tonsillitis, sore throat [26], as flavoring agent, carminative and diuretic [27]. Moreover, this plant has recently been reported with excellent pharmacological activities [28, 29].

Based on the literature survey and ethnomedicinal relevance of $R$. hastatus, this study was designed to evaluate the anti-tumor and anti-angiogenic potentials of $R$. hastatus and to corroborate this plant as a possible remedy of neoplasia.

\section{Results}

\section{Anti-tumor effect}

A general graphical picture based on our potato antitumor and CAM angiogenesis results is summarized as Fig. 1. The anti-tumor assay carried out for various samples of $R$. hastatus revealed a dose dependent anti-tumor response (Table 1). Among the test samples, the saponins showed excellent anti-tumor activity i.e., $93.3 \pm 0.0,83.3 \pm 1.9,78.9 \pm 1.1,63.3 \pm 1.9,56.6 \pm 3.8$ and $53.3 \pm 0.0 \%$ at concentrations of $1000,500,250$, $125,62.5$ and $31.25 \mu \mathrm{g} / \mathrm{ml}$ respectively with $\mathrm{IC}_{50}$ value of $18.1 \mu \mathrm{g} / \mathrm{ml}$. The second highest activity has been attributed to chloroform fraction i.e., $86.7 \pm 3.8,77.8 \pm 1.1$, $70.0 \pm 0.0,65.5 \pm 1.1,58.9 \pm 2.2$ and $50.0 \pm 1.9 \%$ at 1000 , 500, 250, 125, 62.5 and $31.25 \mu \mathrm{g} / \mathrm{ml}$ respectively with $\mathrm{IC}_{50}$ of $31.6 \mu \mathrm{g} / \mathrm{ml}$. Similarly at $1000 \mu \mathrm{g} / \mathrm{ml}$, the Rh.Cr, Rh.Hex, Rh.Chf, Rh.EtAc and Rh.Aq exhibited $85.5 \pm 1.1$, $63.3 \pm 1.9,86.7 \pm 3.8,80.0 \pm 1.9$ and $46.7 \pm 0.0 \%$ tumor inhibitions respectively. A brief summary of cluster analysis of $\mathrm{IC}_{50}$ values are given in Fig. 2 and pictures from the original results of different tested fractions are represented as Fig. 3.

\section{Anti-angiogenic effect}

Various samples of $R$. hastatus showed notable antiangiogenic activity in CAM assay as presented in Table 2 .

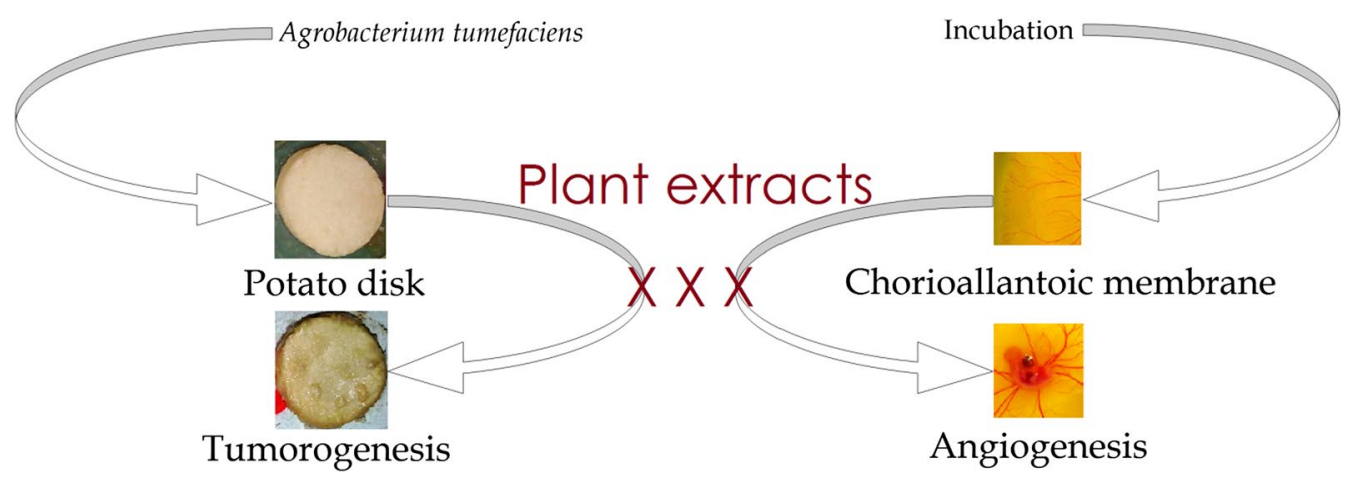

Fig. 1 Graphical presentation of potato disc anti-tumor assay (Left) and CAM angiogenesis assay (Right) 
Table 1 Anti-tumor activity of various samples of Rumex hastatus

\begin{tabular}{|c|c|c|c|c|}
\hline Samples & $\begin{array}{l}\text { Concentra- } \\
\text { tions } \\
(\mu \mathrm{g} / \mathrm{ml})\end{array}$ & $\begin{array}{l}\text { Average } \\
\text { inhibition } \\
\text { (mean } \pm \text { SEM) }\end{array}$ & $\begin{array}{l}\text { Percent } \\
\text { inhibition } \\
\text { (mean } \pm \text { SEM) }\end{array}$ & $\begin{array}{l}\mathrm{IC}_{50} \\
(\mu \mathrm{g} / \mathrm{ml})\end{array}$ \\
\hline \multirow[t]{6}{*}{$\mathrm{Rh} . \mathrm{Cr}$} & 1000 & $25.7 \pm 0.3$ & $85.5 \pm 1.1^{* * *}$ & 197.9 \\
\hline & 500 & $19.0 \pm 0.6$ & $63.3 \pm 1.9^{* * *}$ & \\
\hline & 250 & $16.0 \pm 1.2$ & $53.3 \pm 3.8^{* * *}$ & \\
\hline & 125 & $13.3 \pm 0.3$ & $44.4 \pm 1.1^{* * *}$ & \\
\hline & 62.5 & $12.0 \pm 0.0$ & $40.0 \pm 0.0^{* * *}$ & \\
\hline & 31.25 & $10.0 \pm 0.6$ & $33.3 \pm 1.9^{* * *}$ & \\
\hline \multirow[t]{6}{*}{ Rh.Hex } & 1000 & $19.0 \pm 0.6$ & $63.3 \pm 1.9^{* * *}$ & 395.1 \\
\hline & 500 & $16.3 \pm 0.3$ & $54.4 \pm 1.1^{* * *}$ & \\
\hline & 250 & $12.7 \pm 0.3$ & $42.2 \pm 1.1^{* * *}$ & \\
\hline & 125 & $11.0 \pm 1.2$ & $36.7 \pm 3.8^{* * *}$ & \\
\hline & 62.5 & $10.7 \pm 0.3$ & $35.5 \pm 1.1^{* * *}$ & \\
\hline & 31.25 & $08.0 \pm 0.0$ & $26.7 \pm 0.0^{* * *}$ & \\
\hline \multirow[t]{6}{*}{ Rh.Chf } & 1000 & $26.0 \pm 1.2$ & $86.7 \pm 3.8^{*}$ & 31.6 \\
\hline & 500 & $23.3 \pm 0.3$ & $77.8 \pm 1.1^{* *}$ & \\
\hline & 250 & $21.0 \pm 0.0$ & $70.0 \pm 0.0^{* * *}$ & \\
\hline & 125 & $19.7 \pm 0.3$ & $65.5 \pm 1.1^{* *}$ & \\
\hline & 62.5 & $17.7 \pm 0.7$ & $58.9 \pm 2.2^{* * *}$ & \\
\hline & 31.25 & $15.0 \pm 0.6$ & $50.0 \pm 1.9^{* * *}$ & \\
\hline \multirow[t]{6}{*}{ Rh.EtAc } & 1000 & $24.0 \pm 0.6$ & $80.0 \pm 1.9^{* *}$ & 62.5 \\
\hline & 500 & $19.7 \pm 0.7$ & $65.5 \pm 2.2^{* * *}$ & \\
\hline & 250 & $18.0 \pm 0.6$ & $60.0 \pm 1.9^{* * *}$ & \\
\hline & 125 & $16.0 \pm 1.2$ & $53.3 \pm 3.8^{* * *}$ & \\
\hline & 62.5 & $15.0 \pm 0.0$ & $50.0 \pm 0.0^{* * *}$ & \\
\hline & 31.25 & $13.0 \pm 1.2$ & $43.3 \pm 3.8^{* * *}$ & \\
\hline \multirow[t]{6}{*}{ Rh.Aq } & 1000 & $14.0 \pm 0.0$ & $46.7 \pm 0.0^{* * *}$ & 1138.9 \\
\hline & 500 & $12.6 \pm 0.3$ & $42.2 \pm 1.1^{* * *}$ & \\
\hline & 250 & $11.6 \pm 0.3$ & $38.9 \pm 1.1^{* * *}$ & \\
\hline & 125 & $09.0 \pm 0.6$ & $30.0 \pm 1.9^{* * *}$ & \\
\hline & 62.5 & $08.7 \pm 0.3$ & $28.9 \pm 1.1^{* * *}$ & \\
\hline & 31.25 & $05.3 \pm 0.3$ & $17.8 \pm 1.1^{* * *}$ & \\
\hline \multirow[t]{6}{*}{ Rh.Sp } & 1000 & $28.0 \pm 0.0$ & $93.3 \pm 0.0^{\text {ns }}$ & 18.1 \\
\hline & 500 & $25.0 \pm 0.6$ & $83.3 \pm 1.9^{*}$ & \\
\hline & 250 & $23.7 \pm 0.3$ & $78.9 \pm 1.1^{*}$ & \\
\hline & 125 & $19.0 \pm 0.6$ & $63.3 \pm 1.9^{* *}$ & \\
\hline & 62.5 & $17.0 \pm 1.2$ & $56.7 \pm 3.9^{* * *}$ & \\
\hline & 31.25 & $16.0 \pm 0.0$ & $53.3 \pm 0.0^{* *}$ & \\
\hline
\end{tabular}

Vincristine sulfate was used as positive control having $\mathrm{IC}_{50}$ value $<0.1 \mu \mathrm{g} / \mathrm{ml}$; ${ }^{*}<0.05,{ }^{* *}<0.01,{ }^{* * *}<0.001$

$R h$.Cr crude methanolic extract, Rh.Hex $n$-hexane fraction, Rh.Chf chloroform fraction, Rh.EtAc ethyl acetate fraction, $R h . A q$ aqueous fraction, $R h . S p$ saponins ns Non-significant

The highest anti-angiogenic potential has been demonstrated by Rh.Chf in concentration dependent manner i.e., $56.7 \pm 1.6,59.3 \pm 0.7,64.7 \pm 1.6,68.3 \pm 0.5$, $74.3 \pm 1.2,81.6 \pm 1.7 \%$ at concentrations of $31.25,62.5$, $125,250,500$ and $1000 \mu \mathrm{g} / \mathrm{ml}$ respectively with $\mathrm{IC}_{50}$ value of $17.9 \mu \mathrm{g} / \mathrm{ml}$. Similarly, among the rest of the test samples, the Rh.Sp exhibited good inhibition of angiogenesis with $\mathrm{IC}_{50}$ value of $64.9 \mu \mathrm{g} / \mathrm{ml}$. It is also obvious from the results that all the test samples showed dose dependent response. The result shown by positive control was almost comparable with the Rh.Chf. The order of activity recorded for various samples was Rh.Chf $>$ Rh.Sp $>$ Rh. EtAc $>$ Rh.Cr $>$ Rh.Hex > Rh.Aq with $\mathrm{IC}_{50}$ values of $17.9,64.9,65.5,164.3,1011.5,1034.2 \mu \mathrm{g} / \mathrm{ml}$ respectively as given in Fig. 4 of cluster analysis. A summary of the experimental results in picture form is represented as Fig. 5.

\section{Antibacterial effect}

Antibacterial activity carried out against A. tumefaciens demonstrated negligible activity of various plant samples. This activity was conducted to check that whether the test samples were active against specific strain or not. The antibacterial assay summarized in the Table 3 with minimum inhibitory concentrations (MIC) demonstrates that among the test samples, the Rh.Sp and Rh.Cr were active against the $A$. tumefaciens. The rest of the samples showed no antibacterial activity. Similarly, the result of Rh.Sp ( $\mathrm{MIC}=803.3 \pm 8.8 \mu \mathrm{g} / \mathrm{ml}$ ) and Rh.Cr ( $\mathrm{MIC}=1478.3 \pm 4.4 \mu \mathrm{g} / \mathrm{ml})$ were insignificant in comparison with the positive control (MIC for Ceftriaxone $=7.5 \pm 1.4 \mu \mathrm{g} / \mathrm{ml}$, MIC for Cefotaxime $=18.3 \pm 0.6 \mu \mathrm{g} / \mathrm{ml}$ ) which reveals that the $R$. hastatus is not active against $A$. tumefaciens. Briefly, the antibacterial assay of $R$. hastatus against $A$. tumefaciens does not reveal any significant antibacterial potential in comparison with positive control.

\section{Discussion}

Anti-angiogenic and anti-tumor assays being non-invasive were carried out on fertilized eggs and potato discs respectively in our current investigational study. Herein, we have attempted to explore novel and natural source of anti-angiogenic and anti-tumor compounds due to high efficacy and low toxicity of natural products as compared to the synthetic compounds [5]. The purpose of employing the potato disc method and CAM assay was to get a rapid, economic and reliable results for anti-tumor and anti-angiogenesis potentials [30]. A dose dependent activity of various samples of $R$. hastatus was observed in both assays. The inhibitory effect of each sample has been expressed in percent and median inhibitory concentrations i.e., $\mathrm{IC}_{50}$. The assay is based on the hypothesis that anti-tumor drugs might inhibit the growth of tumors both in plant and animals, since some tumorigenic mechanisms are quite related in plants and animals [31]. A sound correlation has been demonstrated between the anti-tumor activity of bioactive compounds against 3PS 


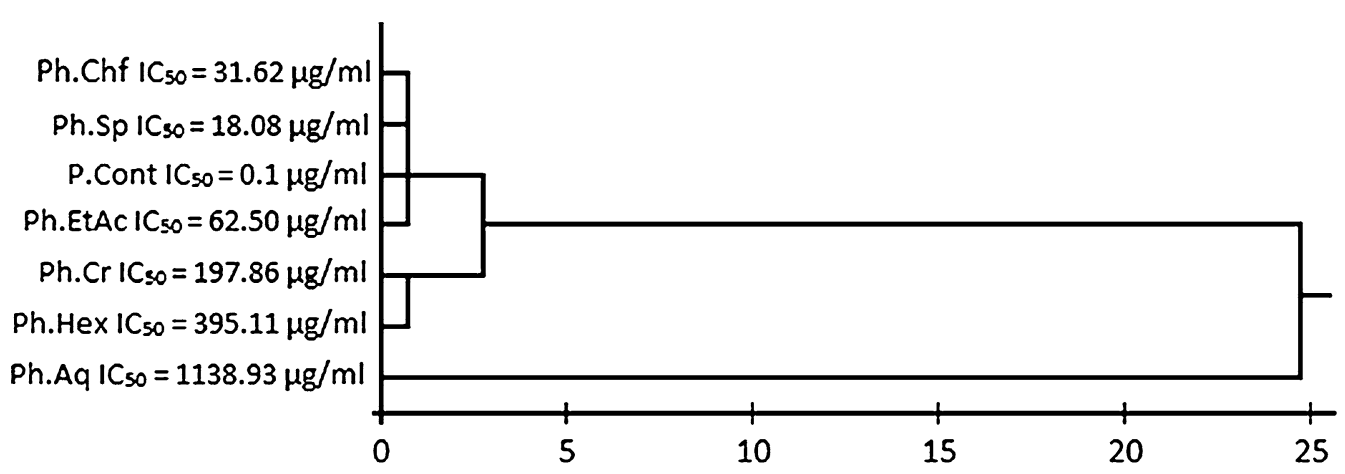

Fig. 2 Cluster analysis and dendrogram based IC50 values of various samples of Rumex hastatus in anti-tumor assay. Rh.Cr Crude methanolic extract, Rh.Hex $n$-hexane fraction, $R$ h.Chf chloroform fraction, Rh.EtAc ethyl acetate fraction, Rh.Aq aqueous fraction, Rh.Sp saponins, P.Cont positive control

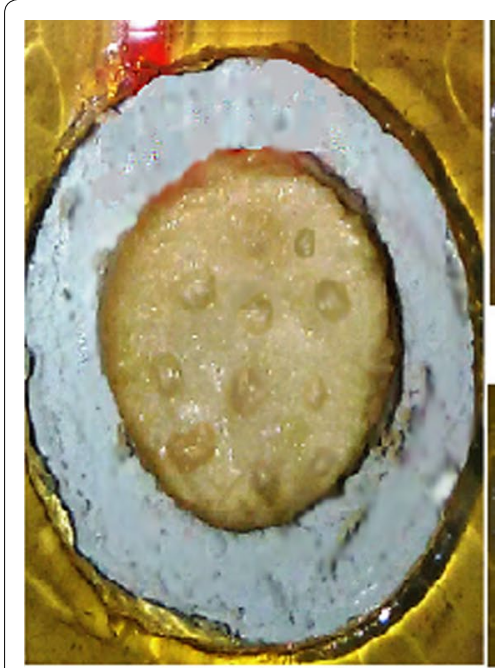

Negative control

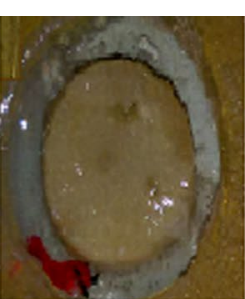

Crude methanolic

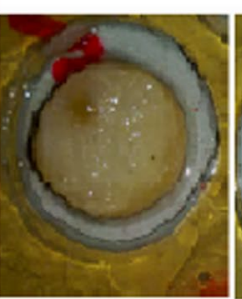

Chloroform

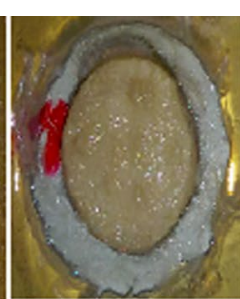

n-hexane

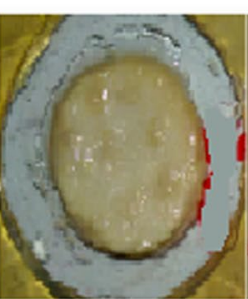

Ethyl acetate

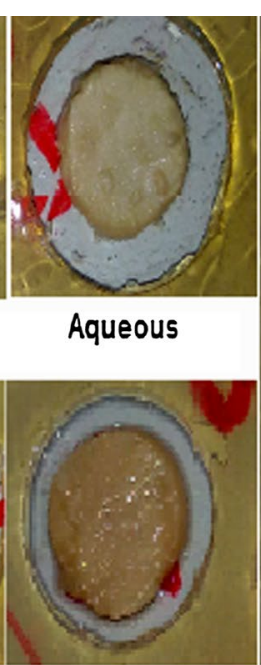

Saponins

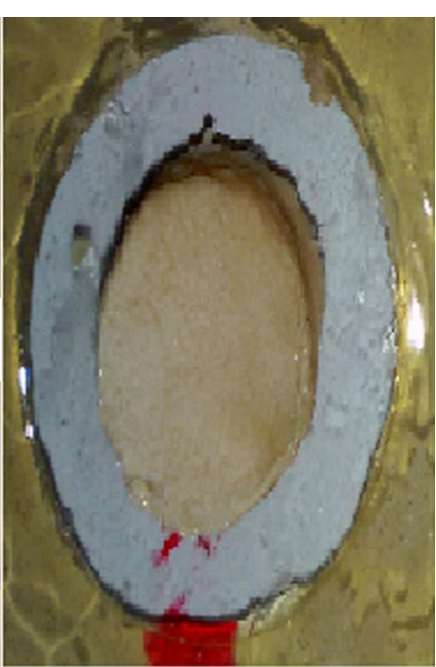

Positive control

Fig. 3 Antitumor activity of various samples of Rumex hastatus along with positive and negative controls. Positive control used was applied with vincristine sulphate and Agrobacterium tumefaciens while the negative control was only applied with Agrobacterium tumefaciens

Table 2 Results of anti-angiogenic assay of various samples of Rumex hastatus

\begin{tabular}{|c|c|c|c|c|c|c|c|}
\hline Samples & Conc. $31.25 \mu \mathrm{g} / \mathrm{ml}$ & Conc. $62.5 \mu \mathrm{g} / \mathrm{ml}$ & Conc. $125 \mu \mathrm{g} / \mathrm{ml}$ & Conc. $250 \mu \mathrm{g} / \mathrm{ml}$ & Conc. $500 \mu \mathrm{g} / \mathrm{ml}$ & Conc. $1000 \mu \mathrm{g} / \mathrm{ml}$ & $\mathrm{IC}_{50} \mu \mathrm{g} / \mathrm{ml}$ \\
\hline Rh.Cr & $39.3 \pm 0.7^{* * *}$ & $43.5 \pm 0.6^{* * *}$ & $48.7 \pm 0.8^{* * *}$ & $54.1 \pm 0.2_{* * *}$ & $62.4 \pm 0.3^{* * *}$ & $71.3 \pm 1.3^{* * *}$ & 164.3 \\
\hline Rh.Hex & $27.3 \pm 1.3^{* * *}$ & $32.9 \pm 0.5^{* * *}$ & $36.7 \pm 0.8^{* * *}$ & $41.9 \pm 0.3^{* * *}$ & $43.0 \pm 0.2^{* * *}$ & $47.2 \pm 1.1^{* * *}$ & 1011.5 \\
\hline Rh.Chf & $56.7 \pm 1.6^{*}$ & $59.3 \pm 0.6^{* *}$ & $64.7 \pm 1.6$ & $68.3 \pm 0.5^{*}$ & $74.3 \pm 1.2^{*}$ & $81.6 \pm 1.7^{*}$ & 17.9 \\
\hline Rh.EtAc & $43.3 \pm 0.6^{* * *}$ & $49.6 \pm 0.8^{* *}$ & $55.3 \pm 0.3^{* *}$ & $61.0 \pm 1.2^{* * *}$ & $67.3 \pm 0.7^{* * *}$ & $72.3 \pm 1.2^{* * *}$ & 65.5 \\
\hline Rh.Aq & $11.6 \pm 1.7$ & $16.0 \pm 1.1$ & $23.3 \pm 1.2$ & $33.3 \pm 0.3$ & $37.0 \pm 1.6$ & $46.3 \pm 0.4$ & 1034.2 \\
\hline Rh.Sp & $43.4 \pm 0.9^{* * *}$ & $49.1 \pm 1.4^{* *}$ & $54.0 \pm 0.6^{* *}$ & $67.9 \pm 0.5^{* *}$ & $71.4 \pm 0.3^{* * *}$ & $78.9 \pm 1.0^{* *}$ & 64.9 \\
\hline
\end{tabular}

Dexamethasone was used as positive control with $\mathrm{IC}_{50}$ value of $11.68 \mu \mathrm{g} / \mathrm{ml}$; data is represented as mean $\pm \mathrm{SEM}$ (Standard Error Mean); ${ }^{*}<0.05,{ }^{* *}<0.01,{ }^{* * *}<0.001$ $R h . C r$ crude methanolic extract, Rh.Hex $n$-hexane fraction, Rh.Chf chloroform fraction, Rh.EtAc ethyl acetate fraction, Rh.Aq aqueous fraction, Rh.Sp saponins 


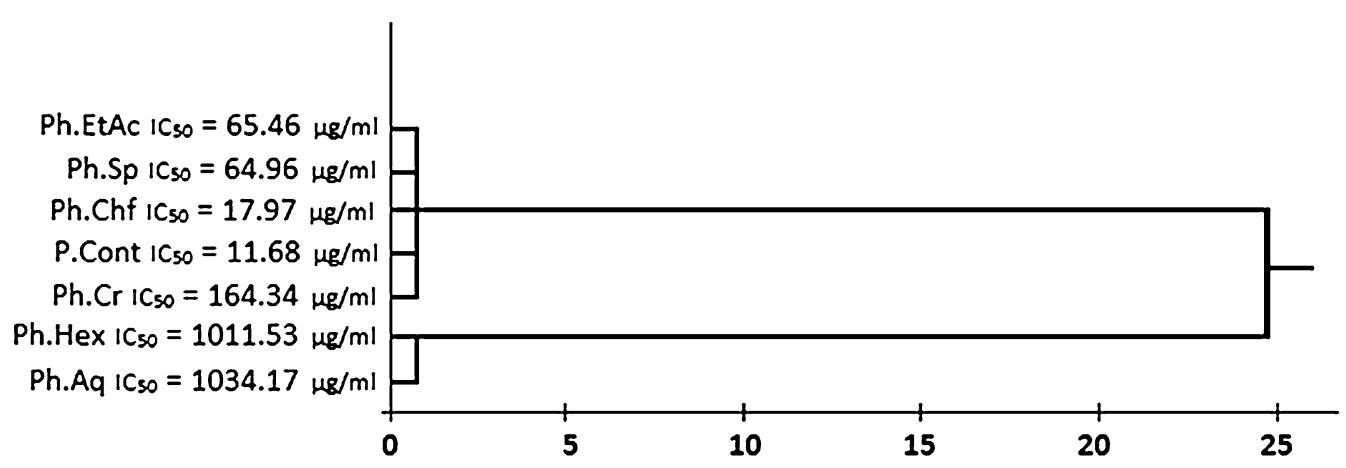

Fig. 4 Cluster analysis and dendrogram based on $I_{50}$ values of various samples of Rumex hastatus in anti-angiogenic activity. Rh. $C r$ Crude methanolic extract, Rh.Hex $n$-hexane fraction, $R$ h.Chf chloroform fraction, Rh.EtAc ethyl acetate fraction, Rh.Aq aqueous fraction, Rh.Sp saponins, P.Cont positive control

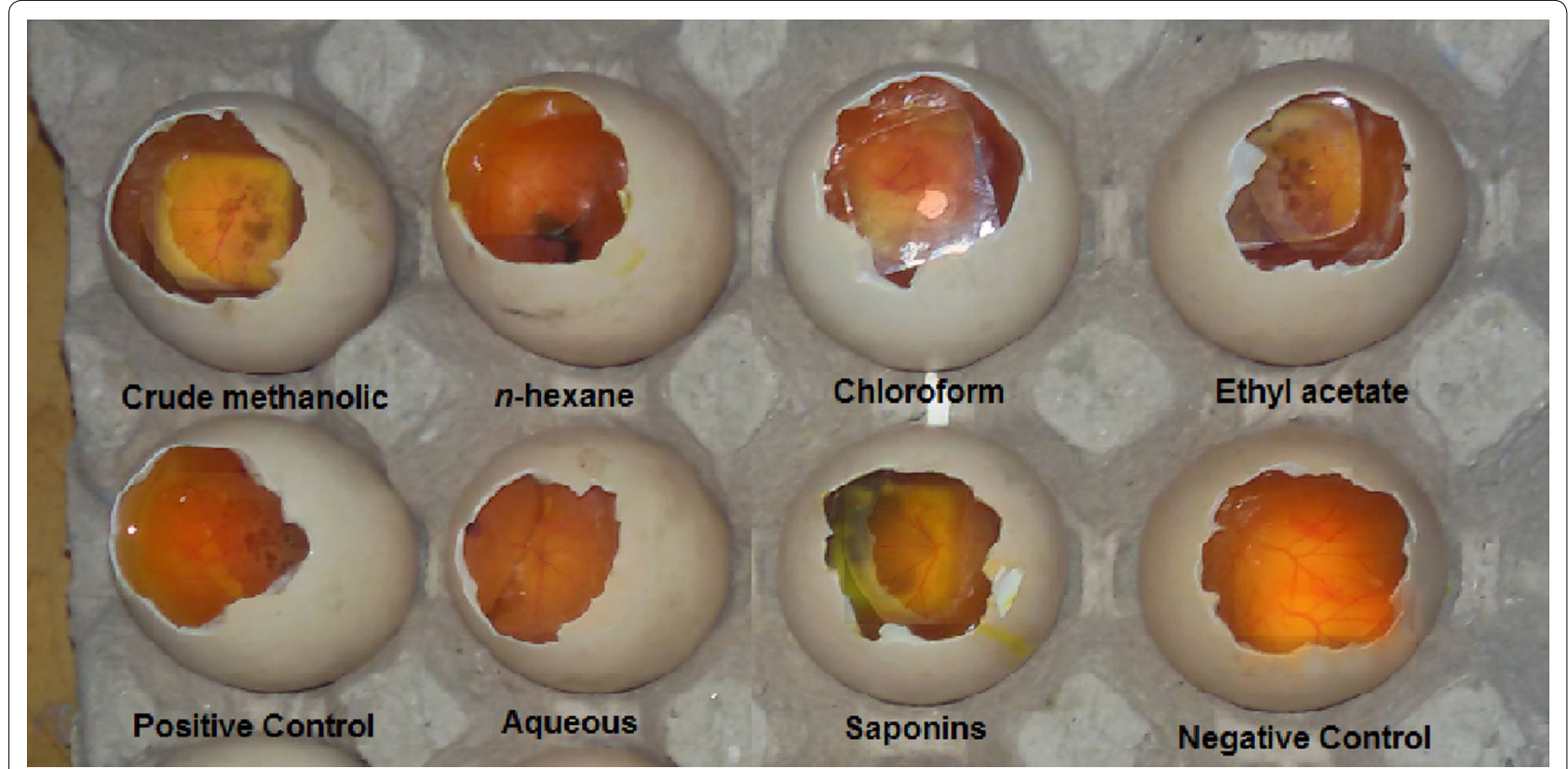

Fig. 5 Anti-angiogenic activity of various samples of Rumex hastatus along with positive and negative control. Positive control CAM was applied with dexamethasone

in murine leukemia and potato tuber discs [32]. The inhibition of A. tumefaciens induced tumor is based on antimitotic activity and potato tumor assay can well demonstrate the 3PS activity as compared to 9 PS or the $9 \mathrm{~KB}$ cytotoxicity assay [33].

The angiogenesis process is described by migration of vascular endothelial cells from parental vessels, invasion through the matrix, proliferation and formation of capillary tube $[34,35]$. While the anti-angiogenic agents bring about the inhibition of proteases, suppression of phosphorylation of receptors or disruption of endothelial tube formation [36, 37]. The anti-tumor potential exhibited by some samples of $R$. hastatus is stronger than several previously reported examples of various plants $[10,11]$. The highest activity shown by methanolic extract of Rumex dentatus had been recorded as $56.6 \%$, which is lower than the least active sample of current investigation [38]. Likewise, the anti-angiogenic potential of $R$. hastatus is comparable with several plant species having strong antiangiogenic potentials [13]. Moreover, the anti-angiogenic potential of various samples of $R$. hastatus is higher than the previously reported that daidzein and genistein [39].

In our current findings it has been demonstrated that various samples of $R$. hastatus were significantly effective 
Table 3 Antibacterial activity of various samples of Rumex hastatus against Agrobacterium tumefaciens

\begin{tabular}{|c|c|c|c|}
\hline Samples & $\begin{array}{l}\text { Concentrations } \\
(\mathrm{mg} / \mathrm{ml})\end{array}$ & $\begin{array}{l}\text { Zones of } \\
\text { inhibition }\end{array}$ & $\mathrm{MIC}(\mu \mathrm{g} / \mathrm{ml})$ \\
\hline \multirow[t]{4}{*}{$\mathrm{Rh} . \mathrm{Cr}$} & 10 & $11.1 \pm 0.4$ & $1478.3 \pm 4.4$ \\
\hline & 5 & $09.3 \pm 0.7$ & \\
\hline & 2.5 & NA & \\
\hline & 1.25 & NA & \\
\hline \multirow[t]{4}{*}{ Rh.Hex } & 10 & NA & - \\
\hline & 5 & NA & \\
\hline & 2.5 & NA & \\
\hline & 1.25 & NA & \\
\hline \multirow[t]{4}{*}{ Rh.Chf } & 10 & NA & - \\
\hline & 5 & NA & \\
\hline & 2.5 & NA & \\
\hline & 1.25 & NA & \\
\hline \multirow[t]{4}{*}{ Rh.EtAc } & 10 & NA & - \\
\hline & 5 & NA & \\
\hline & 2.5 & NA & \\
\hline & 1.25 & NA & \\
\hline \multirow[t]{4}{*}{ Rh.Aq } & 10 & NA & - \\
\hline & 5 & NA & \\
\hline & 2.5 & NA & \\
\hline & 1.25 & NA & \\
\hline \multirow[t]{4}{*}{ Rh.Sp } & 10 & $15.5 \pm 0.8$ & $803.3 \pm 8.8$ \\
\hline & 5 & $13.0 \pm 0.4$ & \\
\hline & 2.5 & $11.9 \pm 0.4$ & \\
\hline & 1.25 & NA & \\
\hline \multirow[t]{4}{*}{ Ceftriaxone } & 10 & $21.5 \pm 1.2$ & $7.5 \pm 1.4$ \\
\hline & 5 & $19.2 \pm 0.3$ & \\
\hline & 2.5 & $17.5 \pm 0.9$ & \\
\hline & 1.25 & $13.6 \pm 0.7$ & \\
\hline \multirow[t]{4}{*}{ Cefotaxime } & 10 & $16.1 \pm 0.4$ & $18.3 \pm 0.6$ \\
\hline & 5 & $11.3 \pm 0.7$ & \\
\hline & 2.5 & $09.3 \pm 0.7$ & \\
\hline & 1.25 & NA & \\
\hline
\end{tabular}

Values are expressed as mean \pm SEM

$R h . C r$ crude methanolic extract, $R h$.Hex $n$-hexane fraction, $R h$.Chf chloroform fraction, Rh.EtAc ethyl acetate fraction, Rh.Aq aqueous fraction, Rh.Sp saponins

to inhibit the tumor in potato disc model and angiogenesis in CAM assay. It has also been revealed that the test samples (except Rh.Sp and Rh.Cr) were inactive against the A. tumefaciens responsible for tumor induction in potato disc. It has also been observed that the anti-angiogenic and antitumor effects of certain fractions (Rh.Sp and Rh.Chf) were comparable with the positive controls as obvious from the Tables 1 and 2. Similarly, the cluster analysis of $\mathrm{IC}_{50}$ values can easily demonstrate the high potency of Rh.Sp and Rh.Chf in Figs. 2 and 4. Our study can be a part of serendipitous and intriguing findings for the upcoming researchers for the isolation of bioactive compounds from the highly active fractions of $R$. hastatus. The anti-tumor and anti-angiogenic activity of various samples of $R$. hastatus indicates the presence of bioactive principles within the highly active fractions. Based on the current investigational study, it is evidenced that the Rh.Sp and Rh.Chf might be good sources of bioactive principles which can impede the neo-vascularization and metastasis.

\section{Conclusions}

Our results reveal that $R$. hastatus possesses strong antitumor and anti-angiogenic potentials. The chloroform fraction and crude saponins were most effective against tumor and angiogenesis. The Rh.Sp was negligibly active against $A$. tumefaciens but still can be considered for the antitumor research in the future. The most suitable target for the isolation of anti-neoplastic bioactive molecules will be Rh.Chf which was active in both activities and inactive against $A$. tumefaciens.

\section{Methods}

\section{Chemicals and drugs}

The solvents used in the current study were of pure HPLC grade (Sigma Aldrich). Vincristine sulphate, dexamethasone, cefotaxime and ceftriaxone were acquired from Sigma Aldrich distributors Peshawar Khyber Pakhtunkhwa Pakistan.

\section{Plant collection and extraction}

The aerial parts of Rumex hastatus were collected in April from the proximity of University of Malakand. The plant was identified by Dr. Ali Hazrat, Plant Taxonomist, Department of Botany, Shaheed Benazir Bhutto University, Sheringal Dir Upper, KPK, Pakistan with voucher specimen 1015SA. It was shade dried for 15 days followed by grinding using a cutter mill. The powdered sample $(7 \mathrm{~kg})$ was subjected to maceration by dipping in $80 \%$ methanol. After maceration for 15 days, it was filtered followed by evaporation of solvent under reduced pressure at $40{ }^{\circ} \mathrm{C}$ using rotary evaporator $[40,41]$. Similarly, the crude methanolic extract (Rh.Cr) obtained was $400 \mathrm{~g}$ (5.7\%).

\section{Fractionation}

The crude methanolic extract (Rh.Cr) having weight of $300 \mathrm{~g}$ was suspended in sufficient amount of water followed by fractionation with various solvents in separating funnel. The fractionation was started with less polar $n$-hexane $(500 \mathrm{ml} \times 3)$, then with chloroform $(500 \mathrm{ml} \times 3)$, then with ethyl acetate $(500 \mathrm{ml} \times 3)$ and finally the aqueous fraction was obtained $[42,43]$.

Similarly, the fractions achieved were 19 (6.3\%), 21 (7\%), 29 (9.6\%) and 120 (40\%) g of $n$-hexane (Rh.Hex), 
chloroform (Rh.Cf), ethyl acetate (Rh.EtAc) and aqueous fraction (Rh.Aq) respectively.

\section{Extraction of crude saponins}

For the extraction of crude saponins from $R$. hastatus, the plant powder having weight of $20 \mathrm{~g}$ was put in a conical flask and $100 \mathrm{ml}$ of $20 \%$ ethanol was added to the conical flask. The sample was heated at $55^{\circ} \mathrm{C}$ in the water bath for $4 \mathrm{~h}$ with continuous stirring. After $4 \mathrm{~h}$ the sample obtained was filtered and the residue having greenish color was re-extracted with $200 \mathrm{ml}$ of $20 \%$ ethanol. The sample after extraction was heated until a concentrated volume of $40 \mathrm{ml}$ was obtained. The sample obtained was transferred into a separating funnel and $20 \mathrm{ml}$ of diethyl ether was added to it. After vigorous shaking, the separating funnel was put in a stand to get two layered sample. The lower layer was collected, which was aqueous layer while the upper diethyl ether layer was discarded. The aqueous layer obtained was diluted with $60 \mathrm{ml}$ of $n$-butanol and the combined $n$-butanol extract was washed with $10 \mathrm{ml}$ of $5 \%$ sodium chloride solution. The final solution obtained was kept in a hot water bath until complete evaporation and the saponins obtained were dried in an oven yielding $1.3 \mathrm{~g}$ of crude saponin $[44,45]$.

\section{Anti-tumor assay}

Suspension of Agrobacterium tumefaciens $1 \times 10^{9}$ colony forming units (CFU) was prepared in phosphate buffered saline. The suspension was standardized at $600 \mathrm{~nm}$ by an absorbance value of $0.96 \pm 0.02$ [46]. Stock solutions of plant samples were prepared and serially diluted to get the concentrations of $1000,500,250$ and $125 \mu \mathrm{g} / \mathrm{ml}$. The concentrations obtained were filtered into ependorf tubes using a sterile millipore filter $(0.2 \mu)$ to get sterilized. To each concentration $0.1 \mathrm{ml}$ of $A$. tumefaciens broth culture were added and vertexed to mix well. Same procedure was followed for positive control i.e., vincristine sulfate while for negative control distilled water having $0.1 \mathrm{ml}$ bacterial culture was used. Similarly red skinned potatoes were surface-sterilized for $30 \mathrm{~min}$ using $0.5 \%$ sodium dichloroisocynnurate solution. These potatoes were then washed thoroughly using sterilized distilled water and aseptically dried. Discs having diameter of $1.5 \mathrm{~cm}$ and thickness of $0.5 \mathrm{~cm}$ were prepared from these potatoes using sterilized cork borer in aseptic environment. These discs were transferred into sterilized petri plates having solidified agar media. To each of the disc $50 \mu \mathrm{l}$ of extractbacterium mixture was applied using sterilized micropipette. Same procedure was followed for positive control while for negative control the distilled water having bacterial culture was applied on potato disc. The triplicate of each sample was used in this study. The petri plates were kept in the incubator (BOD incubator HYSC korea, model: $\mathrm{Bl}-81 / 150 / 250)$ at $25{ }^{\circ} \mathrm{C}$ for 18 days. After 18 days the surface of discs were stained with iodine solution and the number of tumors in each disc were counted with the help of binocular.

\section{Chick chorioallantoic membrane (CAM) assay}

In the current study the fertilized chicken eggs were used to carry out CAM assay [47]. Fresh eggs were kept at $37^{\circ} \mathrm{C}$ in incubator (BOD incubator HYSC korea, model: Bl-81/150/250) with narrow end down. The eggs were moved three to four times on daily basis. At fourth day, the eggs were examined and the head of embryo were encircled using a torch. One $\mathrm{ml}$ of albumen was sucked out from the narrow end of the eggs using 18-gauge hypodermic needle in order to move away the yolk sac and CAM from the shell. Similarly, the shell on the floor of the air sac was punched and peeled away. The thermanox coverslip already loaded with various concentrations of test samples was kept on the CAM surface so that the CAM surface come in contact with the test samples. After applying various samples the eggs were put back into the incubator. After 2 days a small volume of acetone and methanol (1:1) was infused into chorioallantois using 33-gauge needle. The CAM was carefully separated from the egg, the vessels were observed under microscope and number of vessels especially the vessels converging towards the center were calculated. For each test sample 18 eggs were used in this study. Dexamethasone was used as positive control while normal saline was used as negative control. The percent inhibition of angiogenesis was calculated using the following formula:

$$
\% \text { Inhibition }=\frac{\mathrm{CAM}_{\mathrm{ns}}-\mathrm{CAM}_{\mathrm{ts}}}{\mathrm{CAM}_{\mathrm{ns}}} \times 100
$$

$\mathrm{CAM}_{\mathrm{ns}}$ (number of blood vessels in CAM treat with normal saline); $\mathrm{CAM}_{\mathrm{ts}}$ (number of blood vessels in CAM treated with test samples).

\section{Antibacterial assay \\ Preparation and standardization of inoculums}

Agrobacterium tumefaciens were cultured in petri plates having sterile nutrient agar media. Bacterial culture was transferred aseptically into sterile water for injection using wire loop. Suspension of bacterial culture was prepared having cell density of $1 \times 10^{6} \mathrm{CFU} / \mathrm{ml}$ using McFarland standard. Suspension was standardized using UV-visible spectrophotometer and the standardization was maintained at $625 \mathrm{~nm}$ during the whole investigational study.

\section{Well diffusion assay}

Antibacterial activity of various samples $R$. hastatus were investigated against Agrobacterium tumefaciens using 
well diffusion assay $[29,48]$. Plates were prepared using nutrient agar media, labeled and test organism was inoculated under laminar flow hood aseptically. In each petri plate wells $(5 \mathrm{~mm})$ were bored using a sterile cork borer. Various concentrations $(10,5,2.5,1.25 \mathrm{mg} / \mathrm{ml})$ of plant samples were prepared by serial dilution method. Test samples having volume of $100 \mu$ l were transferred into each well. After addition of test samples, the petri plates were incubated for $24 \mathrm{~h}$ at $37{ }^{\circ} \mathrm{C}$. Cefotaxime were used as positive control. Similarly, the zone of inhibition of all the test samples was measured after incubation and the data obtained in triplicate was expressed as mean \pm SEM.

\section{Determination of minimum inhibitory concentrations (MICs)}

For determination of MICs of various test samples, broth dilution method was followed. Stock solution was prepared for each sample having concentration of $5 \mathrm{mg} /$ $\mathrm{ml}$. From stock solution various dilutions were prepared using nutrient broth i.e., from $5 \mathrm{mg} / \mathrm{ml}$ to $0.61 \mu \mathrm{g} / \mathrm{ml}$. To each sample $0.2 \mathrm{ml}$ of bacterial suspension was added using a sterile micropipette. After inoculation, these samples were incubated at $37{ }^{\circ} \mathrm{C}$ for $24 \mathrm{~h}$. After incubation, these samples were observed for turbidity and the minimum concentration, at which there was no bacterial growth was considered as the MIC of a specific test sample [49].

\section{Statistical analysis}

Two-way ANOVA followed by Bonferroni post test were applied for the comparison of positive control with the test groups. $P$ values less than or equal to 0.05 were considered statistically significant. GraphPad Prism, SPSS software and Excel sheet were used to carry out Twoway ANOVA, cluster analysis and calculation $\mathrm{IC}_{50}$ values respectively. The standard error mean (SEM) were calculated at $95 \%$ confidence intervals.

\section{Authors' contributions \\ SA and AZ performed the experimental work under the supervision of FU. FU and MA helped in literature survey and helped in writing the manuscript. AS monitored the overall work and refined the manuscript before final version. All authors read and approved the final manuscript.}

\section{Author details}

${ }^{1}$ Department of Pharmacy, University of Malakand, Chakdara, Dir (L), Khyber-Pakhtunkhwa (KPK) 18000, Pakistan. ${ }^{2}$ Department of Pharmacy, Kohat University of Science and Technology, Kohat, Khyber-Pakhtunkhwa (KPK) 26000, Pakistan.

\section{Acknowledgements}

The authors are thankful to Dr. Ali Hazrat for identification of the plant.

\section{Competing interests}

The authors declare that they have no competing interests.

\section{Funding}

This research received no specific grant from any funding agency in the public, commercial, or not-for-profit sectors.
Received: 24 March 2015 Accepted: 3 March 2016

Published online: 12 March 2016

\section{References}

1. Rao K, Sunitha C, Banji D, Shwetha S, Krishna D. Diuretic activity on different extracts and formulation on aerial parts of Rumex vesicarius Linn. J Chem Pharm Res. 2011;3(6):400-8.

2. Folkman J. The role of angiogenesis in tumor growth. Semin Cancer Biol. 1992;1992:65-71.

3. Carmeliet $P$, Jain RK. Angiogenesis in cancer and other diseases. Nature. 2000;407(6801):249-57.

4. Losso JN. Targeting excessive angiogenesis with functional foods and nutraceuticals. Trends Food Sci Technol. 2003;14(11):455-68.

5. Coats JR. Risks from natural versus synthetic insecticides. Ann Rev Entomol. 1994;39(1):489-515.

6. Lapoint J, James L, Moran C, Nelson L, Hoffman R, Moran J. Severe toxicity following synthetic cannabinoid ingestion. Clin Toxicol. 2011;49(8):760-4.

7. Ashton CJ. Synthetic cannabinoids as drugs of abuse. Curr Drug Abuse Rev. 2012;5(2):158-68.

8. Shah S, Shah SMM, Ahmad Z, Yaseen M, Shah R, Sadiq A, Khan S, Khan B. Phytochemicals, in vitro antioxidant, total phenolic contents and phytotoxic activity of Cornus macrophylla wall bark collected from the north-west of Pakistan. Pak J Pharm Sci. 2015;28(1):23-8.

9. Zeb A, Sadiq A, Ullah F, Ahmad S, Ayaz M. Investigations of anticholinestrase and antioxidant potentials of methanolic extract, subsequent fractions, crude saponins and flavonoids isolated from Isodon rugosus. Biol Res. 2015;47:76

10. Hussain A, Zia M, Mirza B. Cytotoxic and antitumor potential of Fagonia cretica L. Turk J Biol. 2007;31:19-24.

11. Haque N, Chowdhury S, Nutan M, Rahman G, Rahman K, Rashid M. Evaluation of antitumor activity of some medicinal plants of Bangladesh by potato disk bioassay. Fitoterapia. 2000;71(5):547-52.

12. Miura T, Yuan L, Sun B, Fujii H, Yoshida M, Wakame K, Kosuna K-I. Isoflavone aglycon produced by culture of soybean extracts with basidiomycetes and its anti-angiogenic activity. Biosci Biotechnol Biochem. 2002;66(12):2626-31.

13. Wang S, Zheng Z, Weng Y, Yu Y, Zhang D, Fan W, Dai R, Hu Z. Angiogenesis and anti-angiogenesis activity of Chinese medicinal herbal extracts. Life Sci. 2004;74(20):2467-78.

14. Da Rocha AB, Lopes RM, Schwartsmann G. Natural products in anticancer therapy. Curr Opin Pharmacol. 2001;1(4):364-9.

15. Lee N-J, Choi J-H, Koo B-S, Ryu S-Y, Han Y-H, Lee S-I, Lee D-U. Antimutagenicity and cytotoxicity of the constituents from the aerial parts of Rumex acetosa. Biol Pharm Bull. 2005;28(11):2158-61.

16. Hawas UW, Ahmed EF, Abdelkader AF, Taie H. Biological activity of flavonol glycosides from Rumex dentatus plant, an Egyptian xerophyte. J Med Plants Res. 2011;5(17):4239-43.

17. Xie Q-C, Yang Y-P. Anti-proliferative of physcion 8-O-beta-glucopyranoside isolated from Rumex japonicus Houtt on A549 cell lines via inducing apoptosis and cell cycle arrest. BMC Complemet Altern Med. 2014;14(1):377.

18. Buchalter $L$, Cole JR. Isolation of a potential antitumor fraction from Rumex hymenosepalus (Polygonaceae) II. Identification of the active fraction. J Pharm Sci. 1967;56(8):1033-4.

19. Sher $\mathrm{H}$, Hussain F. Ethnobotanical evaluation of some plant resources in northern part of Pakistan. Afr J Biotechnol. 2009;8(17):4066-76.

20. Jan G, Khan MA, Gul F. Ethnomedicinal plants used against jaundice in Dir Kohistan valleys (NWFP), Pakistan. Ethnobot leaflets. 2009;2009(8):7.

21. Peakall R, Gilmore S, Keys W, Morgante M, Rafalski A. Cross-species amplification of soybean (Glycine max) simple sequence repeats (SSRs) within the genus and other legume genera: implications for the transferability of SSRs in plants. Mol Biol Evolution. 1998;15(10):1275-87.

22. Pande P, Tiwari L, Pande H. Ethnoveterinary plants of Uttaranchal-a review. Ind J Trad Knowl. 2007:6(3):444-58.

23. Shinwari ZK, Gilani SS. Sustainable harvest of medicinal plants at Bulashbar Nullah, Astore (northern Pakistan). J Ethnopharmacol. 2003;84(2):289-98. 
24. Gorsi MS, Miraj S. Ethnomedicinal survey of plants of Khanabad village and its allied areas, district Gilgit. Asian J Plant Sci. 2002;1(5):604-15.

25. Manan Z, Razzaq A, Islam M. Diversity of medicinal plants in Wari subdivision district Upper Dir. Pakistan. Pak J Plant Sci. 2007:45:231-4.

26. Taylor R, Hudson J, Manandhar N, Towers G. Antiviral activities of medicinal plants of southern Nepal. J Ethnopharmacol. 1996;53(2):105-10.

27. Ullah A, Rashid A, Parveen SN. Medicinal plants used in the isolated region of Bumburet, Kalash valley, district Chitral, Pakistan. Pak J Weed Sci Res. 2014;20(3):359-73.

28. Ahmad S, Ullah F, Sadiq A, Ayaz M, Imran M, Ali I, Zeb A, Ullah F, Raza Shah M. Chemical composition, antioxidant and anticholinesterase potentials of essential oil of Rumex hastatus D. Don collected from the north west of Pakistan. BMC Complement Altern Med. 2016;16:19.

29. Zul K, Midrarullah SA, Farhat U, Abdul S, Muhammad A, Anwar Z, Muhammad I. Ex-vivo antibacterial, phytotoxic and cytotoxic, potential in the crude natural phytoconstituents of Rumex hastatus D Don. Pak J Bot. 2015:47:293-9.

30. Mclaughlin JL, Rogers LL, Anderson JE. The use of biological assays to evaluate botanicals. Drug info J. 1998;32(2):513-24.

31. Braun A. The relevance of plant tumor systems to an understanding of the basic cellular mechanisms underlying tumorigenesis. Progress Exp Tumor Res. 1971;15:165-87.

32. Galsky AG, Wilsey JP, Powell RG. Crown gall tumor disc bioassay a possible aid in the detection of compounds with antitumor activity. Plant Physiol. 1980;65(2):184-5

33. Ferrigni N, Putnam J, Anderson B, Jacobsen L, Nichols D, Moore D, McLaughlin J, Powell R, Smith C Jr. Modification and evaluation of the potato disc assay and antitumor screening of Euphorbiaceae seeds. J Nat Prod. 1982;45(6):679-86.

34. Pugh CW, Ratcliffe PJ. Regulation of angiogenesis by hypoxia: role of the HIF system. Nat Med. 2003;9(6):677-84.

35. Folkman J. Angiogenesis. Annu Rev Med. 2006;57:1-18.

36. Martin S, Murray JC. Angiogenesis protocols. New York: Springer; 2009.

37. Ferrara N. Vascular endothelial growth factor: basic science and clinical progress. Endocrine Rev. 2004;25(4):581-611.

38. Fatima N, Zia M, Rehman R, Rizvi ZF, Ahmad S, Mirza B, Chaudhary MF. Biological activities of Rumex dentatus L: evaluation of methanol and hexane extracts. Afr J Biotechnol. 2009:8:24.

39. Krenn L, Paper D. Inhibition of angiogenesis and inflammation by an extract of red clover (Trifolium pratense L.). Phytomedicine. 2009;16(12):1083-8.
40. Ayaz M, Junaid M, Ahmed J, Ullah F, Sadiq A, Ahmad S, Imran M. Phenolic contents, antioxidant and anticholinesterase potentials of crude extract, subsequent fractions and crude saponins from Polygonum hydropiper $\mathrm{L}$. BMC Complement Altern Med. 2014;14(1):145.

41. Ahmad S, Ullah F, Ayaz M, Sadiq A, Imran M. Antioxidant and anticholinesterase investigations of Rumex hastatus D. Don: potential effectiveness in oxidative stress and neurological disorders. Biol Res. 2015;48(1):20.

42. Ayaz M, Junaid M, Subhan F, Ullah F, Sadiq A, Ahmad S, Imran M, Kamal Z, Hussain S, Shah SM. Heavy metals analysis, phytochemical, phytotoxic and anthelmintic investigations of crude methanolic extract, subsequent fractions and crude saponins from Polygonum hydropiper L. BMC Complement Altern Med. 2014;14(1):465.

43. Kamal Z, Ullah F, Ayaz M, Sadiq A, Ahmad S, Zeb A, Hussain A, Imran M. Anticholinesterse and antioxidant investigations of crude extracts, subsequent fractions, saponins and flavonoids of Atriplex laciniata L.: potential effectiveness in Alzheimer's and other neurological disorders. Biol Res. 2015:48(1):21.

44. Zeb A, Sadiq A, Ullah F, Ahmad S, Ayaz M. Phytochemical and toxicological investigations of crude methanolic extracts, subsequent fractions and crude saponins of Isodon rugosus. Biol Res. 2014;47(1):57.

45. Ahmad S, Ullah F, Ayaz M, Sadiq A, Zeb A, Imran M. Pharmacological evaluation of saponins, methanolic extract and subsequent fractions of Rumex hastatus D. Don against Monomorium pharaonis and Heterotermis indicola. Pharmacologyonline. 2015;1:13-8.

46. Coker P, Radecke J, Guy C, Camper N. Potato disc tumor induction assay: a multiple mode of drug action assay. Phytomedicine. 2003;10(2):133-8.

47. Nguyen M, Shing Y, Folkman J. Quantitation of angiogenesis and antiangiogenesis in the chick embryo chorioallantoic membrane. Microvascular Res. 1994;47(1):31-40.

48. Imran M, Ullah F, Sadiq A, Ayaz M, Ahmad S, Kamal Z, Zeb A. Investigation of total phenolic contents, antibacterial, antifungal and anthelmintic potentials of crude methanolic extract, subsequent fractions and crude saponins of Nonea micrantha Boiss. and Reut. Pharmacologyonline. 2014;3:26-31.

49. Usman H, Abdulrahman F, Ladan A. Phytochemical and antimicrobial evaluation of Tribulus terrestris L. (Zygophylaceae). Growing in Nigeria. Res J Biol Sci. 2007;3:244-7.

\section{Submit your next manuscript to BioMed Central and we will help you at every step:}

- We accept pre-submission inquiries

- Our selector tool helps you to find the most relevant journal

- We provide round the clock customer support

- Convenient online submission

- Thorough peer review

- Inclusion in PubMed and all major indexing services

- Maximum visibility for your research

Submit your manuscript at www.biomedcentral.com/submit

\section{() Biomed Central}

